\title{
Application of cyanated asphaltenes in gas-phase adsorption processes for removal of volatile organic compounds
}

\author{
Maksymilian Plata-Gryl $^{1}$ (D) $\cdot$ Malwina Momotko $^{1} \cdot$ Sławomir Makowiec $^{2}$ (D) $\cdot$ Grzegorz Boczkaj $^{1}$ (D)
}

Received: 4 June 2019 / Accepted: 14 September 2019 / Published online: 21 September 2019

(c) The Author(s) 2019

\begin{abstract}
The paper presents an innovative, chemically modified (methylcyanated) asphaltene-based adsorbent that can be an interesting low-cost alternative for traditional adsorbents. Adsorption properties of adsorbents were examined by inverse gas chromatography technique, adsorption isotherms, and breakthrough curves. A significant increase in retention volume for pyridine, 2-pentanone, nitropropane, toluene, and 1-butanol was observed. Rohrschneider-McReynolds constants revealed an increase in strength of interactions as a result of the modification, especially in strong proton-acceptor interaction (by a factor of 4.6). The surface-free energy of asphaltene adsorbents increased from 136.71 to $169.95 \mathrm{~mJ} \mathrm{~m}^{-2}$ after modification. It is similar to the surface-free energy of silica or alumina. Moreover, modified adsorbent shows very high adsorption potential for pyridine. Adsorption isotherms revealed that monolayer adsorption capacity for pyridine increased 1.5 times after modification. Breakthrough curves of pyridine indicate that chemical modification increased the adsorption capacity, removal efficiency, and throughput. Scale-up calculations revealed that adsorption column packed with modified asphaltene adsorbent would be almost two times smaller compared to a column packed with unmodified one.
\end{abstract}

\section{Graphic abstract}

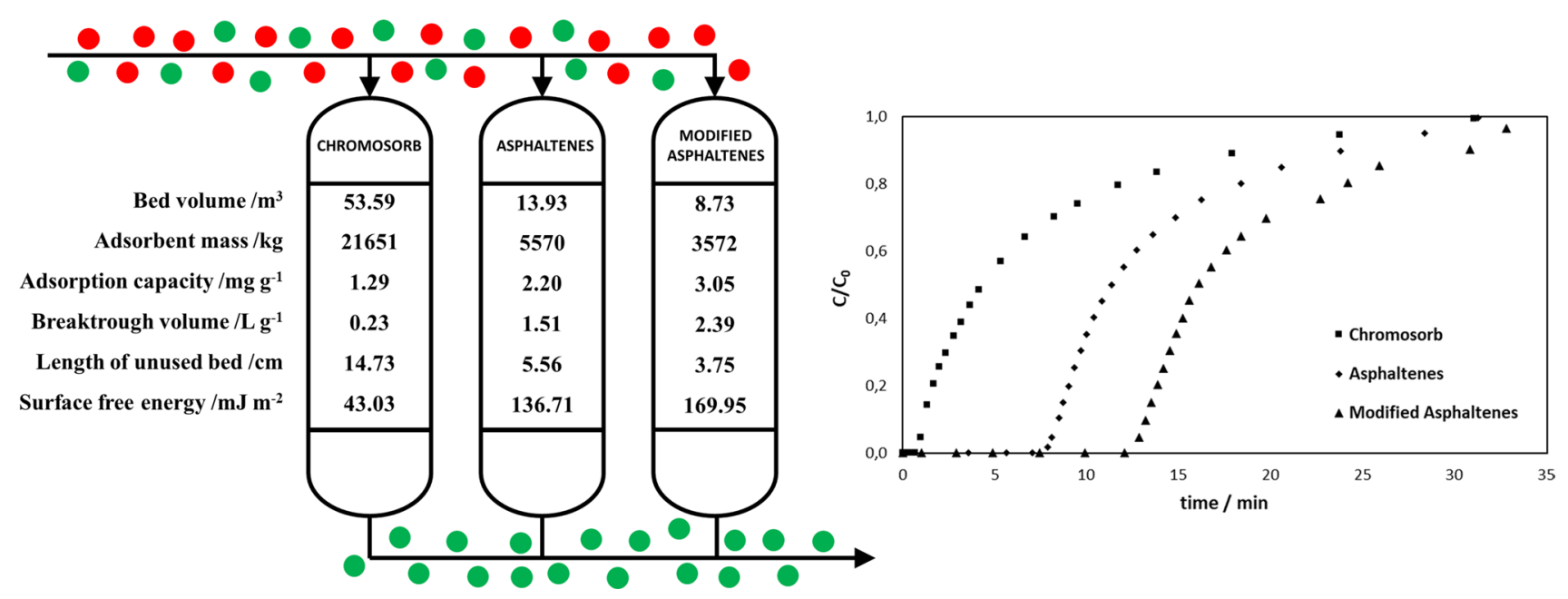

This work was presented at the 44th International Conference of Slovak Society of Chemical Engineering held in Tatranské Matliare on May 21-25, 2018.

Electronic supplementary material The online version of this article (https://doi.org/10.1007/s11696-019-00938-z) contains supplementary material, which is available to authorized users.

Extended author information available on the last page of the article 
Keywords Asphaltenes · Adsorption · Adsorbent · Adsorption isotherms · Breakthrough $\cdot$ VOCs removal

\section{Introduction}

Volatile organic compounds (VOC), according to European Union regulations, it is any organic compound having an initial boiling point less than or equal to $250{ }^{\circ} \mathrm{C}$ measured at a standard pressure of $101.3 \mathrm{kPa}$ (EU 2004). They can cause different diseases and physiological disorders, as well as deteriorate ecosystems (Mellouki et al. 2015; Sarigiannis et al. 2011). VOCs are emitted to the environment from both anthropogenic (e.g., industrial facilities and vehicles) and biogenic sources.

Currently, air quality is gaining more attention as a serious health problem. It leads to tighter legislation standards and increased demand for emission control and waste gas purification techniques. Among those techniques are: thermal oxidation, catalytic oxidation (Huang et al. 2015), absorption (Lin et al. 2006), adsorption (Zhang et al. 2017), biological methods (Gospodarek et al. 2019), and condensation and membrane separation (Belaissaoui et al. 2016).

Adsorption technique is one of the most economical and versatile VOCs' emission control strategies. It is characterized by low energy and maintenance costs, simplicity, and reliability, and can be effectively used to purify waste gases with a low concentration of VOCs. In practice, activated carbons, zeolites, silica, and alumina are used as adsorbents.

Asphaltenes are a class of compounds present in crude oil and products of its processing. It is a fraction insoluble in linear alkanes and soluble in toluene. They quantitatively remain in the residue from vacuum distillation (Mullins 2010, 2011). From a structural standpoint, asphaltenes are polycyclic aromatic hydrocarbons with peripherally attached alkyl chains and graphite-like structure with heteroatoms, e.g., oxygen, nitrogen, sulfur, vanadium, and nickel (Groenzin and Mullins 2000; Schuler et al. 2015). In the petroleum industry, they are a source of severe technological issues (Akbarzadeh et al. 2007). The only practical application of asphaltenes is in the pavement technology as a part of bituminous mixtures.

High thermal stability, feasible procedure of isolation and chemical structure, that can be a source of a vast variety of physicochemical interactions, makes asphaltenes an interesting alternative for traditional adsorbents. In addition, the use of asphaltenes as adsorbents will lead to the valorization of low-value refinery streams (vacuum distillation residues) and will improve waste management. Recently, the applicability of asphaltenes in separation processes was demonstrated (Boczkaj et al. 2016b).

Above-mentioned diverse chemical structure of asphaltene molecules makes them prone to modifications (PlataGryl et al. 2019). This work develops the concept of asphaltene adsorbents, by enhancing asphaltene's adsorption properties through feasible chemical modification. Interactions with noxious VOCs were investigated. For evaluation of surface properties, adsorption capacity and performance before and after modification, breakthrough experiments, and inverse gas chromatography (IGC) were performed. IGC is a versatile characterization technique that is used to investigate surface and bulk properties of solids, e.g., surface-free energy, free energy, enthalpy and entropy of adsorption, and adsorption isotherms (Voelkel et al. 2009).

\section{Experimental}

\section{Asphaltene fraction isolation and chemical modification}

Road bitumen 20/30 SDA (Lotos Group, Gdansk, Poland) and $n$-heptane EMPLURA ${ }^{\circledR}$ (Merck, Darmstadt, Germany) were used to isolate asphaltene fraction. A detailed description of the isolation procedure can be found in (Plata-Gryl et al. 2018).

Chemical modification was performed by dissolving the isolated asphaltene fraction in methylene chloride (p.a., POCH, Gliwice, Poland) in ratio $30 \mathrm{mg}: 1 \mathrm{~mL}$. Next, $1.7 \mathrm{mg}$ of chloroacetonitrile and $0.7 \mathrm{mg}$ of $\mathrm{ZnCl}_{2}$ per $1 \mathrm{mg}$ of asphaltene were added. The obtained mixture was boiled and continuously stirred in an argon atmosphere for $21 \mathrm{~h}$. Afterward, the solvent was evaporated under reduced pressure. The residue was mixed with methanol (p.a., $\mathrm{POCH}$, Gliwice, Poland), and filtered and rinsed with distilled water and methanol. Subsequently, it was dried under vacuum at $82{ }^{\circ} \mathrm{C}$ for $8 \mathrm{~h}$.

The effect of chemical modification on surface structural properties was investigated by Fourier-transform infrared spectroscopy (FTIR) carried out using Bruker TENSOR 27 spectrophotometer (Bruker Optik, Germany) equipped with ATR (Attenuated Total Reflectance) attachment. Asphaltene samples were deposited on the surface of the crystal of the ATR attachment from solution in methylene chloride. Data were recorded in the MIR spectral range from 4000 to $375 \mathrm{~cm}^{-1}$ at a spectral resolution of $4 \mathrm{~cm}^{-1} .256$ scans were averaged for both background and sample spectra.

\section{Adsorbent preparation}

For adsorption experiments, asphaltenes were coated onto inert support, namely Chromosorb W-AW-DMCS 80-100 mesh (Johns Manville, Denver, USA). Full description of the support preparation and coating procedures can be 
found in (Boczkaj et al. 2016b). The aforementioned procedure ensures complete coating of the support's surface and eliminates its interaction with test probes. Prepared adsorbents were dry-packed into stainless steel columns of internal diameter $2.1 \mathrm{~mm}$. Ends of the column were plugged with silanized glass wool. Before adsorption experiments, columns were conditioned in $250{ }^{\circ} \mathrm{C}$ for $5 \mathrm{~h}$ in carrier gas (nitrogen) flow. Prepared adsorbents were denoted as $\mathrm{Ch}-\mathrm{W}$ (uncoated support), Asf (non-modified asphaltenes), and AsfCN (cyanated asphaltenes).

\section{General retention characteristics and selectivity}

General retention characteristics and selectivity of asphaltene-based adsorbents were examined by gas chromatography (GC) technique, based on test mixtures containing various chemical compounds, e.g., aromatics, ketones, alcohol, and sulfides having a concentration of ca. $500 \mathrm{ppm}$ of each probe compound in carbon disulfide (p.a. Merck, Darmstadt, Germany). Full list of test compounds is presented in Table S1. To determine Rohrschneider-McReynolds constants, a standard test mixture of $n$-alkanes from $n$-C $\mathrm{C}_{5}$ to $n-\mathrm{C}_{15}$ (Analytical Controls, Rotterdam, The Netherlands) was used. The void time was determined based on methane retention time as a non-interacting probe (a gas mixture of methane in nitrogen was used for this purpose). GC analyses were performed on the Clarus 500 gas chromatograph (Perkin Elmer, Waltham, USA) equipped with a flame-ionization detector (FID). For this purpose, $3 \mathrm{~m}$ columns were used. In all of the analyses, the injection volume of the test mixture was $1 \mu \mathrm{L}$. During analyses, the following gases were used: nitrogen (carrier gas), air (for FID) (5 N, Linde Gas, Gdansk, Poland), and hydrogen (5.5 N) from hydrogen generator $\mathrm{PGXH}_{2} 500$ (Perkin Elmer, Waltham, USA). Chromatographic separations were carried out with temperature programming: 5 min @ $40^{\circ} \mathrm{C}, 10^{\circ} \mathrm{C} / \mathrm{min}, 5 \min @ 250{ }^{\circ} \mathrm{C}$. Based on retention time values, the following parameters were calculated: capacity factor $(k)$, selectivity coefficient $(\alpha)$, and linear retention index (LRI).

Linear retention index of a given compound on the investigated stationary is calculated according to the following equation:

$\mathrm{LRI}=100\left(\frac{t_{\mathrm{r}, \mathrm{i}}-t_{\mathrm{r}, z}}{t_{\mathrm{r}, z+1}-t_{\mathrm{r}, z}}\right)+100 z$,

where $t_{\mathrm{r}, \mathrm{i}}$ is the retention time of a compound of interest, $t_{\mathrm{r}, \mathrm{z}}$ and $t_{\mathrm{r}, \mathrm{Z}+1}$ are the retention time of $n$-alkanes eluting before and after the compound of interest, respectively, and $z$ is the carbon atom number in the $n$-alkane molecule eluting before compound of interest.

Rohrschneider-McReynolds constants are a widely used concept in gas chromatography to characterize intermolecular forces between separated solutes and the stationary phase. Specific constants are calculated as the difference between retention indices of some specific compounds on the stationary phase studied and squalane (non-polar reference stationary phase). The sum of constants is termed as "polarity" of the stationary phase. Test probes used to determine the Rohrschneider-McReynolds constants and type of interactions which they represent are described in details in Table S2.

\section{Adsorption properties of the adsorbent's surface studies by inverse gas chromatography (IGC)}

To evaluate the surface-free energy of adsorbents, the IGC is performed at infinite dilution (near zero surface coverage). At these conditions, adsorption is described by Henry's law and only adsorbate-adsorbent interactions are observed. To achieve this, small volumes of vapors from the headspace of the probe compounds were injected. Each probe was injected separately.

For IGC experiments, the same apparatus as mentioned above was used. Temperature of GC oven during experiments was maintained at $303 \mathrm{~K}$ and carrier gas flow rate was set to $20 \mathrm{~mL} \mathrm{~min}^{-1}$. The basic parameter used in IGC is net retention volume $V_{\mathrm{N}}$. It was calculated according to Eq. (2):

$V_{\mathrm{N}}=\frac{j}{m} F\left(t_{\mathrm{R}}-t_{0}\right)$,

where $t_{\mathrm{R}}(\mathrm{min})$ is the retention time of a test compound, $t_{0}$ (min) is the void time measured with methane, $F\left(\mathrm{~mL} \min ^{-1}\right)$ is the flow rate measured at the temperature of experiment, $j$ $(-)$ is the James-Martin correction factor for compressibility of the gas (James and Martin 1952), and $m$ (g) is the mass of the adsorbent.

Based on $V_{\mathrm{N}}$, the molar free energy of adsorption $\Delta G_{\mathrm{A}}$ $\left(\mathrm{J} \mathrm{mol}^{-1}\right.$ ) was calculated by Eq. (3):

$\Delta G_{\mathrm{A}}=-R T \ln V_{\mathrm{N}}+C$,

where $R\left(\mathrm{~J} \mathrm{~K}^{-1} \mathrm{~mol}^{-1}\right)$ is the gas constant, $T(\mathrm{~K})$ is the absolute temperature, and $C$ is a constant.

To calculate the free surface energy of a solid, the value of dispersive and specific components must be known. Dispersive component of the surface-free energy $\gamma_{\mathrm{S}}^{\mathrm{D}}$ was calculated from the retention data of $n$-alkanes, since for non-polar probes, only dispersive interactions occur (Voelkel et al. 2009). To calculate the value of $\gamma_{\mathrm{S}}^{\mathrm{D}}$, the Dorris-Gray method was used (Dorris and Gray 1980). Dispersive component was calculated by Eq. (4):

$$
\gamma_{\mathrm{S}}^{\mathrm{D}}=\frac{\left(-\Delta G_{\mathrm{CH}_{2}}\right)^{2}}{4 N^{2}\left(a_{\mathrm{CH}_{2}}\right)^{2} \gamma_{\mathrm{CH}_{2}}},
$$


where $N$ is the Avogadro's number $\left(\mathrm{mol}^{-1}\right)$ and $\Delta G_{\mathrm{CH}_{2}}$ $\left(\mathrm{J} \mathrm{mol}^{-1}\right)$ is the free energy of adsorption per methylene group. $\Delta G_{\mathrm{CH}_{2}}$ is obtained from the slope of the $\Delta G_{\mathrm{A}}$ versus the number of carbon atoms in the $n$-alkane molecule. $a_{\mathrm{CH}_{2}}$ $\left(\mathrm{m}^{2}\right)$ is the surface area of methylene group. For calculation, the most common value of $6 \AA^{2}$, found in the literature, was used. $\gamma_{\mathrm{CH}_{2}}\left(\mathrm{~J} \mathrm{~mol}^{-1}\right)$ is the surface-free energy of the polyethylene-type polymer with finite molecular weight. It was calculated according to Eq. (5) (Voelkel et al. 2009):

$\gamma_{\mathrm{CH}_{2}}=(35.6+0.058(293-T)) \times 10^{-3}$.

To estimate specific interactions, polar test compounds were used. The extent of those interactions can be measured based on the assumption that:

$\Delta G_{\mathrm{A}}=\Delta G_{\mathrm{A}}^{\mathrm{D}}+\Delta G_{\mathrm{A}}^{\mathrm{SP}}$,

where $\Delta G_{\mathrm{A}}^{\mathrm{D}}$ is the dispersive component of the free energy of adsorption (equal to $\Delta G_{\mathrm{A}}$ of $n$-alkanes) and $\Delta G_{\mathrm{A}}^{\mathrm{SP}}\left(\mathrm{J} \mathrm{mol}^{-1}\right)$ is the specific component of the free energy of adsorption. $\Delta G_{\mathrm{A}}^{\mathrm{SP}}$ was calculated by Papirer's method (Saint Flour and Papirer 1982). In this method, a plot of $\Delta G_{\mathrm{A}}$ for series of $n$-alkanes against the logarithm of the saturated vapor pressure $\left(P^{0}\right)$ at the experimental temperature is required. It should give straight line and $\Delta G_{\mathrm{A}}^{\mathrm{SP}}$ can be calculated as a difference between $\Delta G_{\mathrm{A}}$ for a polar probe and a hypothetical $n$-alkane with the same vapor pressure.

Based on the values of $\Delta G_{\mathrm{A}}^{\mathrm{SP}}$, the acidic (electron acceptor) and basic (electron donor) properties of a solid can be estimated. In this work, the Good and van Oss approach (van Oss et al. 1988) was used to obtain acidic $\left(\gamma_{\mathrm{S}}^{+}\right)$and basic $\left(\gamma_{\mathrm{S}}^{-}\right)$ parameters of the asphaltene adsorbents according to Eq. (7):

$\Delta G_{\mathrm{A}}^{\mathrm{SP}}=2 \times N \times a_{\mathrm{P}}\left(\left(\gamma_{1}^{+} \gamma_{\mathrm{S}}^{-}\right)^{\frac{1}{2}}+\left(\gamma_{1}^{-} \gamma_{\mathrm{S}}^{+}\right)^{\frac{1}{2}}\right)$,

where $a_{\mathrm{P}}\left(\mathrm{m}^{2}\right)$ is the cross-sectional area of an adsorbate, and $\gamma_{1}^{+}$and $\gamma_{1}^{-}\left(\mathrm{J} \mathrm{m}^{-2}\right)$ are the electron acceptor and electron donor parameters of a probe molecules, respectively. Similarly, $\gamma_{\mathrm{S}}^{+}$and $\gamma_{\mathrm{S}}^{-}\left(\mathrm{J} \mathrm{m}^{-2}\right)$ are the electron acceptor (acidic) and electron donor (basic) parameters of a solid's surface, respectively. When using monopolar acid $\left(\gamma_{1}^{-}\right.$is $\left.0.0 \mathrm{~J} \mathrm{~m}^{-2}\right)$, Eq. 7 reduces to:

$\gamma_{\mathrm{S}}^{-}=\frac{\left(\Delta G_{\mathrm{A}}^{\mathrm{SP}}\right)^{2}}{4 \times N^{2} \times a^{2} \times \gamma_{1}^{+}}$

conversely; when monopolar base is used $\left(\gamma_{1}^{+}\right.$is $\left.0.0 \mathrm{~J} \mathrm{~m}^{-2}\right)$, Eq. (7) simplifies to:

$\gamma_{\mathrm{S}}^{+}=\frac{\left(\Delta G_{\mathrm{A}}^{\mathrm{SP}}\right)^{2}}{4 \times N^{2} \times a^{2} \times \gamma_{1}^{-}}$.
In this work, chloroform (TCM) was used as a monopolar acid $\left(\gamma_{1}^{+}\right.$is $0.0015 \mathrm{~J} \mathrm{~m}^{-2}$ ) and ethyl acetate (EtOAc) was used as a monopolar base $\left(\gamma_{1}^{-}\right.$is $0.0062 \mathrm{~J} \mathrm{~m}^{-2}$ ) (van Oss 1993). Using the acidic and basic parameters, the specific component of the surface-free energy $\gamma_{\mathrm{S}}^{\mathrm{SP}}$ can be calculated according to the following equation:

$\gamma_{\mathrm{S}}^{\mathrm{SP}}=2 \sqrt{\gamma_{\mathrm{S}}^{+} \gamma_{\mathrm{S}}^{-}}$.

To determine adsorption isotherms, IGC at finite concentration and peak maximum method were used. Details about the method and calculations can be found in (Huber and Gerritse 1971; Kipping and Winter 1965). Experimental conditions (temperature and carrier gas flow rate) were the same as in IGC at infinite dilution experiments. Experimental data were fitted to Langmuir and Freundlich isotherm models.

Langmuir model is a two-parameter model that describes the adsorption on flat homogenous surface with finite number of equivalent adsorption centers which can hold one molecule. According to this model, only monolayer coverage is possible. In non-linear form, Langmuir model is as follows (Langmuir 1918):

$q_{\mathrm{e}}=\frac{Q_{\mathrm{mon}} K_{\mathrm{L}} P}{1+K_{\mathrm{L}} P}$,

where $q_{\mathrm{e}}$ is the amount of adsorbed probe compound (adsorbate) per gram of adsorbent $\left(\mathrm{mg} \mathrm{g}^{-1}\right), P$ is the partial pressure of an adsorbate in gas phase $(\mathrm{Pa}), K_{\mathrm{L}}$ is the Langmuir constant $\left(\mathrm{Pa}^{-1}\right)$, and $Q_{\mathrm{mon}}$ is the maximum monolayer capacity $\left(\mathrm{mg} \mathrm{g}^{-1}\right)$.

Freundlich model is an empirical model which describes non-linear reversible adsorption on energetically heterogeneous surfaces, and in its non-linear form, it is described by Eq. (12) (Jaroniec 1975):

$q_{\mathrm{e}}=K_{\mathrm{F}} P^{1 / n}$,

where $K_{\mathrm{F}}$ is the Freundlich constant $\left(\mathrm{mg} \mathrm{g}^{-1} \mathrm{~Pa}^{-1 / n}\right)$ which can be treated as a rough adsorption capacity indicator and $n$ is the dimensionless constant related to an intensity of adsorption. The lower the value of $n$, the more favorable is adsorption.

Experimental data were fitted by non-linear regression. Computations were performed by $\mathrm{R}$ programming language ( $\mathrm{R}$ : a language and environment for statistical computing 2008) using the minipack.ln package which utilizes Levenberg-Marquardt non-linear least-squares algorithm (Elzhov et al. 2016)

\section{Breakthrough experiments}

Breakthrough curves were measured on modified Autosystem XL gas chromatograph (Perkin Elmer, Waltham, USA) with FID using a $20 \mathrm{~cm}(2.1 \mathrm{~mm}$ ID) long SS columns. As a model contaminant, pyridine in nitrogen (gas mixture, $C=0.88 \mathrm{mg}$ 
$\mathrm{L}^{-1}$ ) was used. All measurements were done in triplicate at $30{ }^{\circ} \mathrm{C}$ and at $50 \mathrm{~mL} / \mathrm{min}$ flow rate. A breakthrough point was set to $C_{\mathrm{t}} / C_{0}=0.05$, where $C_{t}$ is an effluent concentration and $\mathrm{C}_{0}$ is an influent concentration.

Maximum adsorption capacity $q_{\max }(\mathrm{mg})$ of the adsorbent was calculated as follows:

$q_{\max }=F \int_{t=0}^{t_{\mathrm{e}}} C_{\mathrm{r}} \mathrm{d} t$,

where $C_{\mathrm{r}}=\left(C_{0}-C_{t}\right)$ is the pyridine removal $\left(\mathrm{mg} \mathrm{L}^{-1}\right)$ concentration, $C_{0}$ is the initial pyridine concentration $\left(\mathrm{mg} \mathrm{L}^{-1}\right)$, $C_{t}$ is the pyridine concentration in effluent at given time (mg $\mathrm{L}^{-1}$ ), and $t_{\mathrm{e}}$ is exhaustion time (min). The adsorption capacity until breakthrough was calculated from the same formula by changing the integral bound $t_{\mathrm{e}}$ to $t_{\mathrm{b}}$ (breakthrough time at $\left.C_{t} / C_{0}=0.05\right)$. In text, adsorption capacities are reported per gram of adsorbent as $Q_{\max }$ and $Q_{\text {break }}\left(\mathrm{mg} \mathrm{g}^{-1}\right)$.

Breakthrough volume $V_{\text {break }}(\mathrm{L})$ was calculated according to Eq. (14):

$V_{\text {break }}=\frac{F \times t_{\mathrm{b}}}{1000 \times m}$.

In this work, effective adsorption capacity $Q_{\text {eff }}$ is defined as a part of adsorption capacity of an adsorbents utilized up to the breakthrough point and was calculated as:

$Q_{\text {eff }}=\frac{Q_{\text {break }}}{Q_{\max }} \times 100$

Percentage removal of pyridine RE $(\%)$ was calculated by Eq. (16):

$\mathrm{RE}=\frac{q_{\mathrm{max}}}{P_{\text {total }}} \times 100$,

where $P_{\text {total }}(\mathrm{mg})$ is the total amount of pyridine that entered the column calculated according to Eq. (17):

$P_{\text {total }}=\frac{C_{0} F t_{\mathrm{e}}}{1000}$

The mass-transfer zone (MTZ) $(\mathrm{cm})$ is the part of packed bed where adsorption takes place. The shorter the MTZ, the better the performance of adsorption column. MTZ was calculated by the following equation:

$\mathrm{MTZ}=L\left(\frac{t_{\mathrm{e}}-t_{\mathrm{b}}}{t_{\mathrm{e}}}\right)$,

where $L$ is the length of the adsorbent in the column $(\mathrm{cm})$.

Length of unused bed LUB $(\mathrm{cm})$ is the distance of the adsorbent bad, which is not saturated at the breakthrough time. It was calculated as follows:

$\mathrm{LUB}=L\left(\frac{t_{\mathrm{s}}-t_{\mathrm{b}}}{t_{\mathrm{s}}}\right)$, where $t_{\mathrm{s}}$ is the time at which $C_{t} / C_{0}=0.5$.

Adsorbent exhaustion rate $\operatorname{ARE}\left(\mathrm{g} \mathrm{L}^{-1}\right)$ is the mass of adsorbent deactivated per volume of the gas that flew through the column up to breakthrough point. Lower values of AER indicate better column performance. ARE was calculated by Eq. (20):

$\mathrm{AER}=\frac{m}{V_{\text {break }}}$.

For a given adsorbent bed, the performance of a column depends on the number of bed volumes of gas NBV (1) treated before the breakthrough occurs. NBV is expressed as follows:

$\mathrm{NBV}=\frac{V_{\text {break }}}{V_{\text {bed }}}$,

where $V_{\text {bed }}(\mathrm{L})$ is the volume of the adsorbent's bed in the adsorption column.

To analyze the dynamic behavior of pyridine adsorption onto the packed-columns with studied adsorbents, a few frequently used models were used, i.e., Thomas, Yoon-Nelson, Dose Response (DRM), and Bed Depth Service Time (BDST) models were applied to the experimental data. Models were fitted to the data in the same way as in case of adsorption isotherms.

Thomas model can be used to calculate the maximum adsorption capacity. It assumes that the adsorption process follows the second-order reversible kinetics, Langmuir isotherm of adsorption and there is no axial dispersion (Thomas 1944). The mathematical form of Thomas model is as follows:

$\frac{C_{t}}{C_{0}}=\frac{1}{1+\exp \left(\frac{k_{\mathrm{Th}} q_{\mathrm{Th}} m}{F}-k_{\mathrm{Th}} C_{0} t\right)}$,

where $t$ is the experimental time $(\mathrm{h}), k_{\mathrm{Th}}$ is the Thomas rate constant $\left(\mathrm{L} \mathrm{h}^{-1} \mathrm{mg}^{-1}\right), q_{\mathrm{Th}}$ is the maximum adsorption capacity of the adsorbent $\left(\mathrm{mg} \mathrm{g}^{-1}\right)$, and $\mathrm{F}$ is the flow rate in $\mathrm{L} \mathrm{h}^{-1}$.

The Yoon-Nelson is a simple model originally developed for the adsorption of gases on activated carbons (Yoon and Nelson 1984). The model is expressed as follows:

$\frac{C_{t}}{C_{0}}=\frac{1}{1+\exp \left(k_{\mathrm{Yn}}\left(t_{50}-t\right)\right)}$,

where $k_{\mathrm{Yn}}$ is the rate constant $\left(\mathrm{min}^{-1}\right)$ and $t_{50}$ is the time required to reach the point in which $C_{t} / C_{0}=0.5$.

The DRM model (Yan et al. 2001) is represented by Eq. (24):

$\frac{C_{t}}{C_{0}}=1-\frac{1}{1+\left(\frac{C_{0} F t}{q_{\mathrm{DRM}} m}\right)^{a}}$, 
where $a$ is the constant and $q_{\text {DRM }}\left(\mathrm{mg} \mathrm{g}^{-1}\right)$ is the maximum adsorption capacity predicted by the model.

The last model used in this work was the BDST model. The model assumes that adsorption is limited by the adsorbent-adsorbate interactions. It focuses on predicting the time (service time) required to remove a specific amount of adsorbate before exhaustion. The equation describing BDST model is as follows (Hutchins 1973):

$\frac{C_{t}}{C_{0}}=\frac{1}{1+\exp \left[k_{\mathrm{BDST}} C_{0}\left(\frac{N_{0}}{C_{0} u} L-t\right)\right]}$,

where $k_{\mathrm{BDST}}\left(\mathrm{L} \mathrm{mg}^{-1} \mathrm{~min}^{-1}\right)$ is the adsorption rate constant that describes the mass transfer from the gas phase to the solid phase and $N_{0}\left(\mathrm{mg} \mathrm{L}^{-1}\right)$ is the maximum volumetric adsorption capacity of adsorbent's bed.

For scale-up calculations, the breakthrough curves and following kinetic equation were used:

$\frac{C_{t}}{C_{0}}=\frac{1}{1+\exp \left(\frac{k_{1}}{F}\left(q_{0} m-C_{0} V\right)\right)}$,

where $k_{1}\left(\mathrm{~L} \mathrm{~kg}^{-1} \mathrm{~s}^{-1}\right)$ is the rate constant, $q_{0}\left(\mathrm{~kg} \mathrm{~kg}^{-1}\right)$ is the maximum adsorption capacity, and $V(\mathrm{~L})$ is the throughput volume. The advantage of this approach is the possibility to select a breakthrough volume in the design of a column.

\section{Quality assurance of data}

Except for the general retention characteristics, all measurements were performed in triplicates and results are given with $95 \%$ confidence interval CI. It was calculated as:

$\mathrm{CI}=t_{\alpha / 2, d f} \times \mathrm{SE}$,

where $t_{\alpha / 2, d f}$ is a $t$ Student statistic for $95 \%$ confidence level and for given degrees of freedom $d f$. SE is a standard error of a mean value.

To confirm the fit of the data to the models, the determination coefficient $R^{2}$ and Chi-square coefficient $\chi^{2}$ were used. The expressions of $R^{2}$ and $\chi^{2}$ are given below:

$R^{2}=\frac{\sum\left(y_{\mathrm{c}}-\bar{y}_{\mathrm{e}}\right)^{2}}{\sum\left(y_{\mathrm{e}}-\bar{y}_{\mathrm{e}}\right)^{2}}$,

$\chi^{2}=\sum \frac{\left(y_{\mathrm{e}}-y_{\mathrm{c}}\right)^{2}}{y_{\mathrm{c}}}$,

where $y_{\mathrm{c}}, y_{\mathrm{e}}$, and $\bar{y}_{\mathrm{e}}$ are values calculated by a model, experimental, and experimental mean, respectively.

\section{Results and discussion}

Figure S1 presents the FTIR-ATR spectra of raw and modified asphaltenes. Obtained spectra are convoluted and only general features of the surface structure can be identified. Absorption bands near 2920, 2850, 1455, and $1375 \mathrm{~cm}^{-1}$ are characteristics for $\mathrm{CH}_{2}$ and $\mathrm{CH}_{3}$ groups in aliphatic chains. No absorption above $3100 \mathrm{~cm}^{-1}$ indicates lack of $\mathrm{OH}$ groups on the surface of asphaltenes. Absorption bands between 730 and $870 \mathrm{~cm}^{-1}$ can be assigned to aromatic $\mathrm{C}-\mathrm{H}$ out-of-plane bending vibrations (Malhotra and Buckmaster 1989). Band near $1030 \mathrm{~cm}^{-1}$ can be related to ester linkages or sulfoxides (Wilt et al. 1998). Band near $1260 \mathrm{~cm}^{-1}$ can be attributed to groups containing singly bonded oxygen, e.g., esters or ethers (Carbognani and Espidel 2003). The distinct band observed at $1600 \mathrm{~cm}^{-1}$ is related to the aromatic $\mathrm{C}=\mathrm{C}$-stretching vibrations. In the spectrum of Asf, a band from ketonic carbonyl oxygen (band at 1700-1680 $\mathrm{cm}^{-1}$ ) (Ali et al. 2004) is observed, while in AsfCN spectrum, it is missing indicating a change in the surface functional group structure.

Studies by IR spectroscopy revealed slight changes in the surface structure of asphaltenes. It is probably due to complex matrix as asphaltene fraction, which is consisting of hundreds/thousands of different chemical compounds. Strong signal from oxygen containing moieties can shield the signal produced by the functional groups introduced by chemical modification. Moreover, FTIR technique may not be sensitive enough to detect small number of $-\mathrm{CN}$ functional groups. Nevertheless, following results of adsorption studies clearly demonstrate that chemical modification significantly enhanced adsorption performance of asphaltene adsorbents.

\section{General retention characteristics}

Table S1 presents a comparison of the capacity factors $(k)$, selectivity factors with respect to $n$-heptane $\left(\alpha_{\mathrm{C} 7}\right)$, and linear retention indices (LRIs) for the raw and cyanated adsorbents. Based on the values of capacity factors, it can be noticed that chemical modification has changed the selectivity of asphaltenes. On unmodified adsorbent thiophenes, thiols, sulfides, and disulfides presented the order of elution according to the boiling point (lack of unique selectivity) and on cyanated asphaltenes only sulfides, disulfides, and additionally ketones exhibited retention proportional to boiling points. On modified adsorbent, sulfides and disulfides eluted according to boiling points even when considered as one group of compounds. This demonstrates the lack of specific interactions with compounds carrying the sulfur-containing functional groups. 
Interesting retention pattern was revealed for pyridine and its methylated derivatives on the cyanated adsorbent. The elution order was inversely proportional to temperature. The bigger the number of methyl groups attached to the pyridine ring, the lowest retention was observed. It indicates strong interactions with pyridine ring and additional methyl groups introduce steric hindrance that constricts adsorbate-adsorbent interactions.

In general, increased strength of interactions between cyanated adsorbent and test compounds can be observed, comparing to non-modified asphaltenes. Analysis of the values of LRIs indicates uniform change upon modification. An increase in the value of LRIs is about 1.4-1.5 times comparing to non-modified asphaltenes. It was the highest for aromatic hydrocarbons (1.48) and the lowest for alcohols (1.41). Similarly, the most significant change in the selectivity was found for the aromatic hydrocarbons. The biggest increase of $\alpha_{\mathrm{C} 7}$ was for nitrobenzene $(\times 1.80)$ and pyridine $(\times 1.65)$ and the lowest for 2 -pentanone $(\times 1.20)$. Moreover, increase in capacity factor for nitrobenzene and pyridine was observed. It implies that those compounds (and similar ones) can be effectively adsorbed and removed from gaseous streams by the cyanated adsorbent. Consequently, pyridine was selected for experiments in dynamic conditions (breakthrough studies). The second aspect of pyridine selection relates to its odorous character with low odor threshold as well as toxicity.

To preliminary compare types of interactions between adsorbent and adsorbate, the Rohrschneider-McReynolds constants are calculated and presented in Table 1. For comparison purposes, values for adsorbents commonly used in gas chromatography are given as well.

Chemical modification of asphaltenes leads to increased values of all constants indicating an increase in the intermolecular forces between test probes and the adsorbent. The smallest change was observed for $X^{\prime}$, which means that there is relatively small change in the dispersion forces and polarizability character of the adsorbent. Cyanation had the most profound effect on the value of the constant $S^{\prime}$, which represent the acidic character of the adsorbent. Its value increased over four times. That implies stronger interactions with proton-acceptor and polar molecules, such as pyridine. In general, overall "polarity" of the AsfCN was raised by 2.5 times and indicates much stronger interactions (prolonged retention) with adsorbates as compared to unmodified asphaltenes. It must be emphasized that "polarity" of the stationary phase, defined as the sum of the Rohrschneider-McReynolds constants, cannot be equated with selectivity. Simply, the higher the sum ("polarity"), the higher the retention time. Based on the $\Sigma$, AsfCN can be classified as the medium "polarity" adsorbent.

For more in-depth information about surface adsorption properties, the IGC technique was used. Figure 1 compares the retention volumes (expressed as bed volumes, BV) for volatile organic compounds on the investigated adsorbents. The highest retention volume was observed for pyridine. At the same time, the most significant change (over two times) upon modification was observed for pyridine, nitropropane, $n$-butanol, DEE, and TCM. However, in case of DEE and TCM, the overall retention is low as compared to, e.g., pyridine. It is in great part related to differences in boiling points.

\section{Surface characterization by inverse gas chromatography}

In Table 2, values of the dispersive component of the surface-free energy $\left(\gamma_{\mathrm{S}}^{\mathrm{D}}\right)$ and the change of the free enthalpy of adsorption per methylene group $\left(\Delta G_{\mathrm{CH}_{2}}\right)$ for investigated adsorbents are presented. In addition, values reported in the literature for other adsorbents are given. Measurements revealed slight change in the value of $\gamma_{\mathrm{S}}^{\mathrm{D}}$ as a result of chemical modification of asphaltenes. It is in line with small change in the value of Rohrschneider-McReynolds's $X^{\prime}$ constant. Both the constant $X^{\prime}$ and parameter $\gamma_{\mathrm{S}}^{\mathrm{D}}$ represent the ability of an adsorbent to interact by non-specific dispersion forces. It is evident that cyanation did not change that property significantly. Consequently, the differences in retention volumes presented in Fig. 1 have arisen from the change in specific interactions. To some extent, it was disclosed by the aforementioned Rohrschneider-McReynolds constants. Nevertheless, both asphaltene-based adsorbents display

Table 1 Values of the Rohrschneider-McReynolds constants. Under the constant sign, type of represented interaction is given

\begin{tabular}{|c|c|c|c|c|c|c|}
\hline Adsorbent & $\begin{array}{l}X^{\prime} \\
\pi-\pi \text { interaction }\end{array}$ & $\begin{array}{l}Y^{\prime} \\
\text { Hydrogen } \\
\text { bonding }\end{array}$ & $\begin{array}{l}Z^{\prime} \\
\text { Proton- } \\
\text { acceptor }\end{array}$ & $\begin{array}{l}U^{\prime} \\
\text { Dipole-dipole }\end{array}$ & $\begin{array}{l}S^{\prime} \\
\text { Strong proton-- } \\
\text { acceptor interaction }\end{array}$ & $\Sigma$ \\
\hline Asf & 88 & 97 & 172 & 182 & 171 & 710 \\
\hline AsfCN & 102 & 293 & 276 & 325 & 785 & 1781 \\
\hline Apiezon J (non-polar, hydrocarbon type) & 38 & 36 & 27 & 49 & 57 & 207 \\
\hline Carbowax 6000 (very polar, polyglycol) & 322 & 540 & 369 & 577 & 512 & 2320 \\
\hline OV-275 ${ }^{\circledR}$ (highly polar, silicone) & 629 & 872 & 763 & 1106 & 849 & 4219 \\
\hline
\end{tabular}


Fig. 1 Retention volumes (reported as bed volumes) for volatile organic compounds measured at infinite dilution conditions

\begin{tabular}{lllll}
\hline Adsorbent & $T / K$ & $\gamma_{\mathrm{S}}^{\mathrm{D}}\left(\mathrm{mJ} \mathrm{m}^{-2}\right)$ & $\Delta G_{\mathrm{CH}_{2}}\left(\mathrm{~kJ} \mathrm{~mol}^{-1}\right)$ & References \\
\hline Ch-W & 303 & $26.02 \pm 0.01$ & $2.18 \pm 0.08$ & This work \\
Asf & 303 & $106.66 \pm 0.64$ & $4.42 \pm 0.53$ & This work \\
AsfCN & 303 & $118.03 \pm 0.05$ & $4.65 \pm 0.15$ & This work \\
Alumina & 473 & 59.3 & NA & Díaz et al. (2004) \\
Zeolite 13X & 473 & 154.9 & NA & Díaz et al. (2004) \\
Carbon nanofiber & 473 & 18.4 & NA & Díaz et al. (2007) \\
Fumed silica & 293 & $98.2 \pm 2$ & NA & Vidal et al. (1987) \\
Silica & 353 & 61.3 & 6.97 & Tijburg et al. (1991) \\
\hline
\end{tabular}

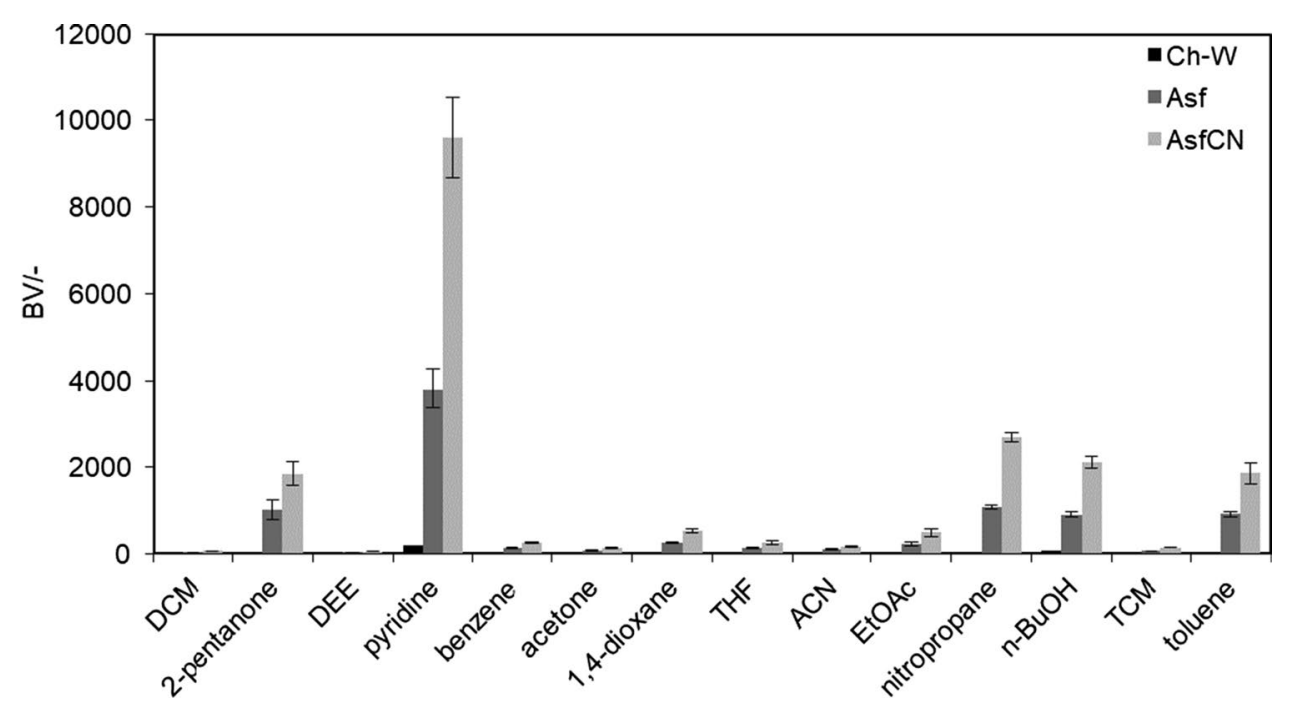

Table 2 Values of the dispersive component of the surface-free energy and the change of the free enthalpy of adsorption per methylene group for investigated adsorbents and selected adsorbents reported in the literature 
Fig. 2 Contribution of specific and dispersive components to the total surface-free energy. Inserted table presents the strength of acid (electron acceptor) and base (electron donor) interactions of asphaltene adsorbents

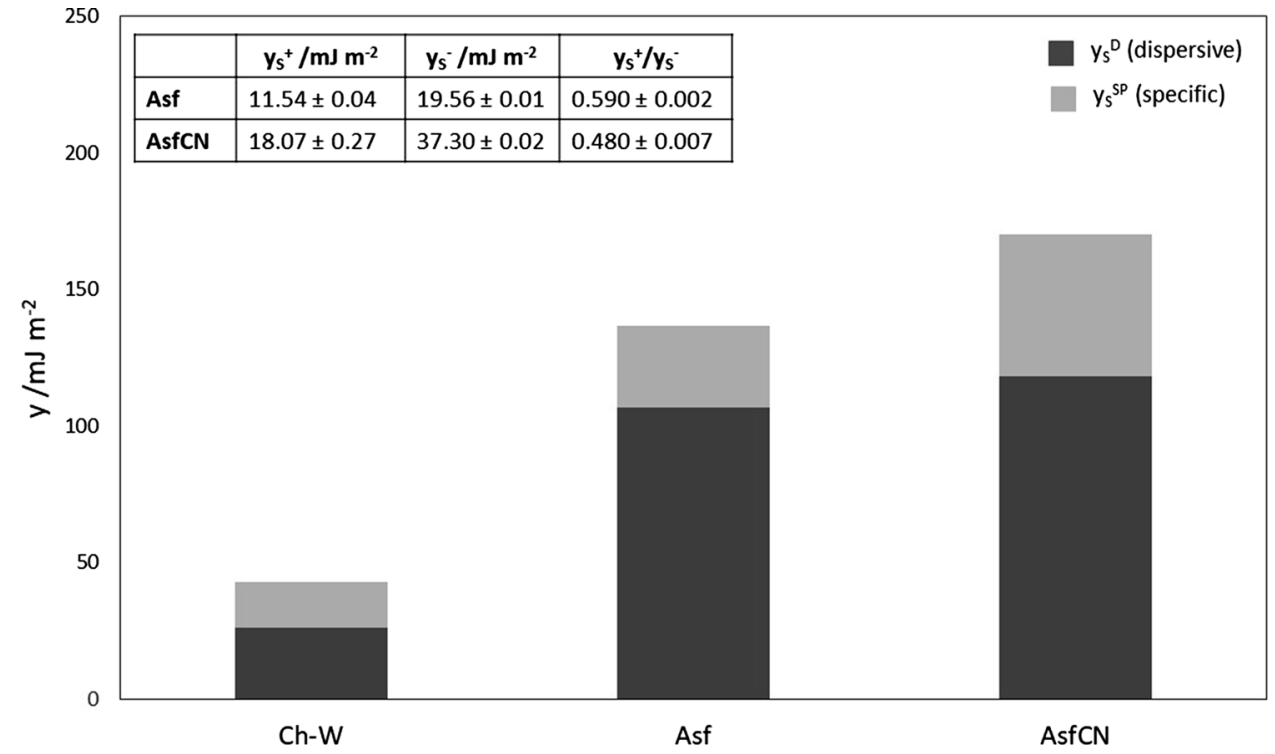

It is clear that the biggest part of adsorbent-adsorbate interactions is due to dispersive forces. That type of interactions has non-specific character and will contribute to the adsorption of chemical compounds regardless their chemical nature. It will be beneficial in case of purification of waste gases containing wide variety of contaminants. Moreover, measurements revealed that most profound difference between the raw and modified asphaltene adsorbent is in the specific component of the surface-free energy. As a result of modification, both acid (electron acceptor) and base (electron donor) adsorption centers were introduced, which is observed by the increased values of the $\gamma_{S}^{+}$and $\gamma_{S}^{-}$. That change was not equal and the surface character, measured by $\gamma_{S}^{+} / \gamma_{S}^{-}$ratio, shifted slightly towards more electron donor (basic). Although the difference is not that substantial and asphaltene adsorbents can be effective in removal of both alkaline and acidic gases.

\section{Adsorption isotherms}

To learn more about adsorption potential of asphaltene adsorbents, an adsorption isotherm for pyridine at $303 \mathrm{~K}$ was measured by IGC at finite concentration. Figure 3 presents the experimental adsorption isotherms together with model isotherms (Langmuir and Freundlich), and in Table 4, the values of the parameters of the isotherm models are presented.

Values of the $R^{2}$ indicate that Freundlich isotherm model fits better to the experimental data. It implies that the surface
Fig. 3 Experimental and model adsorption isotherms for pyridine at $303 \mathrm{~K}$ on asphaltene adsorbents

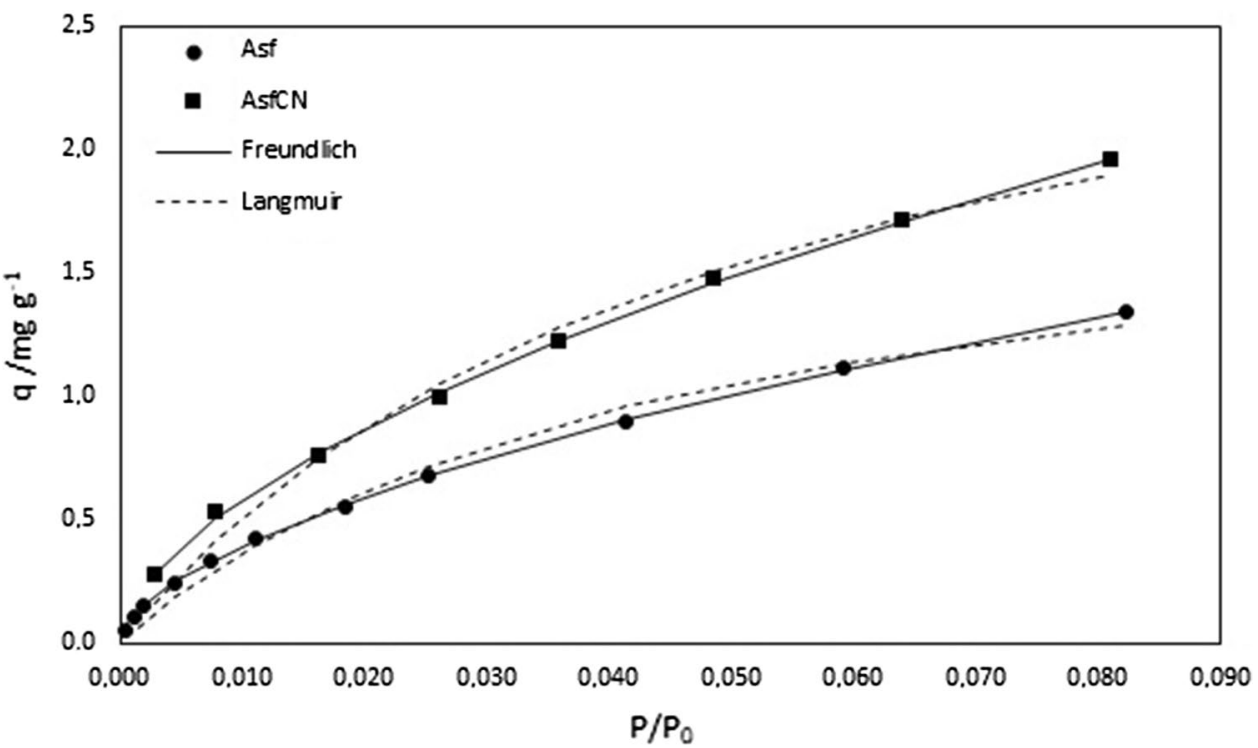


Table 4 Results of the isotherm models fitting to the experimental data

\begin{tabular}{lll}
\hline & Asf & AsfCN \\
\hline Langmuir & & \\
$Q_{\text {mon }}\left(\mathrm{mg} \mathrm{g}^{-1}\right)$ & $1.970 \pm 0,335$ & $3.076 \pm 0.612$ \\
$K_{\mathrm{L}}\left(\mathrm{Pa}^{-1}\right)$ & $0.0063 \pm 0.0021$ & $0.0055 \pm 0.0021$ \\
$R^{2}$ & 0.991 & 0.990 \\
Freundlich & & \\
$n(-)$ & $1.717 \pm 0.029$ & $1.725 \pm 0.047$ \\
$K_{\mathrm{F}}\left(\mathrm{mg} \mathrm{g}^{-1} \mathrm{~Pa}^{-1 / n}\right)$ & $0.049 \pm 0.002$ & $0.073 \pm 0.006$ \\
$R^{2}$ & 1.000 & 0.999 \\
\hline
\end{tabular}

of the adsorbents is heterogeneous. At the same time, similar value of the $n$ parameter of the Freundlich model indicates that chemical modification did not influenced significantly the heterogeneity of the asphaltene adsorbent's surface. $K_{\mathrm{F}}$ parameter can be correlated with the adsorption capacity. Its higher value for AsfCN demonstrates the increased adsorption capacity which is in line with the calculated, from the Langmuir model, monolayer capacity $\left(Q_{\text {mon }}\right)$. The monolayer capacity has increased by $56 \%$ as a result of chemical modification.

\section{Breakthrough experiments}

Since most of the adsorption processes are performed in fixed bed columns with constant flow of a contaminated gas, it was important to evaluate the adsorption performance of the investigated adsorbents in dynamic conditions. Figure 4 presents experimental breakthrough curves, and in Table 5, parameters calculated based on breakthrough data are given.

From breakthrough curves shapes, it is clear that chemical modification enhanced the adsorption properties of
Table 5 Operational parameters of investigated columns for adsorption of pyridine at $303 \mathrm{~K}$ and $50 \mathrm{~mL} \mathrm{~min}^{-1}$ flowrate

\begin{tabular}{lccc}
\hline Parameter & Ch-W & Asf & AsfCN \\
\hline RE $(\%)$ & $23.03 \pm 1.38$ & $45.24 \pm 1.96$ & $54.26 \pm 4.73$ \\
MTZ $(\mathrm{cm})$ & $19.29 \pm 0.12$ & $14.50 \pm 0.48$ & $12.53 \pm 0.51$ \\
LUB $(\mathrm{cm})$ & $14.73 \pm 0.65$ & $5.56 \pm 0.20$ & $3.75 \pm 0.39$ \\
NBV $(-)$ & $81 \pm 1$ & $589 \pm 8$ & $890 \pm 33$ \\
AER $\left(\mathrm{g} \mathrm{L}^{-1}\right)$ & $0.16 \pm 0.01$ & $0.18 \pm 0.01$ & $0.16 \pm 0.01$ \\
$Q_{\text {eff }}(\%)$ & $15.46 \pm 2.70$ & $60.63 \pm 2.75$ & $68.78 \pm 2.24$ \\
$Q_{\text {max }}\left(\mathrm{mg} \mathrm{g}^{-1)}\right.$ & $1.29 \pm 0.06$ & $2.20 \pm 0.08$ & $3.05 \pm 0.23$ \\
$Q_{\text {break }}\left(\mathrm{mg} \mathrm{g}^{-1}\right)$ & $0.20 \pm 0.03$ & $1.33 \pm 0.02$ & $2.10 \pm 0.16$ \\
$V_{\text {break }}\left(\mathrm{L} \mathrm{g}^{-1}\right)$ & $0.23 \pm 0.03$ & $1.51 \pm 0.02$ & $2.39 \pm 0.18$ \\
\hline
\end{tabular}

asphaltene adsorbent. Calculated maximum adsorption capacity $\left(Q_{\max }\right)$ is in very good agreement with the monolayer capacity $\left(Q_{\text {mon }}\right)$ obtained from the Langmuir isotherm model. The experiment confirmed previous observations that both asphaltene adsorbents are superior as compared to $\mathrm{Ch}-\mathrm{W}$ adsorbent. The highest pyridine removal efficiency was obtained for AsfCN and goes along with the highest maximum adsorption capacity $\left(Q_{\max }\right)$, adsorption capacity till breakthrough $\left(Q_{\text {break }}\right)$, and breakthrough volume $\left(V_{\text {break }}\right)$. Moreover, for AsfCN, the highest effectiveness of adsorption capacity exploitation was observed. Up to the breakthrough point, the AsfCN was exhausted in almost $70 \%$. In the case of Ch-W and Asf, it was 15 and 60\%, respectively. Since the exhaustion time was virtually the same for all adsorbents, the change in breakthrough point must have been a result of mass-transfer zone-length change. For AsfCN, the length of MTZ was reduced by $35 \%$ as compared to $\mathrm{Ch}-\mathrm{W}$ and by $13.6 \%$ as compared to the Asf adsorbent. Furthermore, considerable change was observed in the value of NBV. For modified adsorbent, the volume of fluid treated till breakthrough (expressed as bed volumes) was equal to 890 . For
Fig. 4 Breakthrough curves for pyridine $\left(0.88 \mathrm{mg} \mathrm{L}^{-1}\right)$ at $303 \mathrm{~K}$ and at flow rate of $50 \mathrm{~mL} \mathrm{~min}{ }^{-1}$

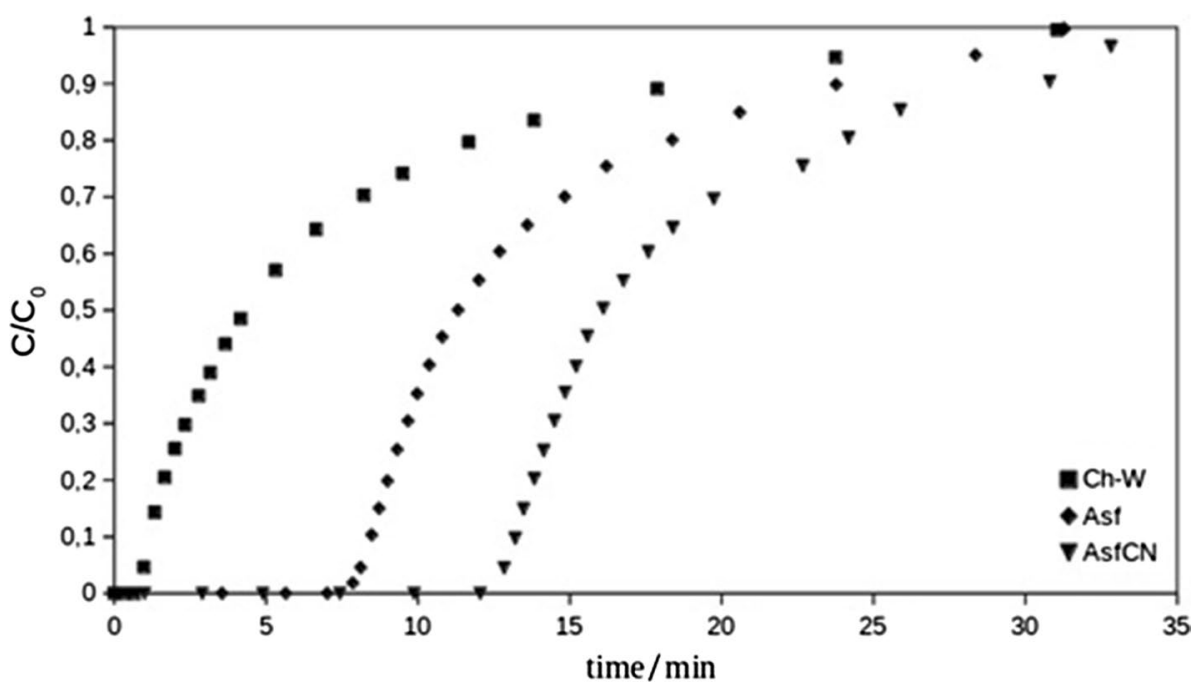


performance, effectiveness and also from an economic point of view, very important is the change in the value of LUB. It describes the part of an adsorbent bed in the column which remains unused when the breakthrough point occurs. In the case of chemically modified asphaltene adsorbent, it was reduced by 400 and $50 \%$ compared to $\mathrm{Ch}-\mathrm{W}$ and Asf, respectively.

Tested adsorption columns undergo three adsorption-desorption cycles. Obtained results showed that the adsorbent can be recycled/reused. Based on the standard deviation value, for three repetitions, it can be seen that prepared adsorbent retained its adsorption properties after several regenerations (Table 5).

To further analyze the obtained breakthrough curves, the experimental data were modeled by the Thomas and BDST models. The results of modeling are presented in Table 6 and Figure S2.

All models used described the experimental data in a reasonably good manner. The determination coefficient was above 0.930 in all cases. However, models failed to predict the experimental breakthrough curve near the inflection points. On both sides of the curve (near the breakthrough and saturation points), models underestimated the performance of adsorbent. Interestingly, three models (Thomas,

Table 6 Thomas, Yoon-Nelson, DRM, and BDST model parameters

\begin{tabular}{|c|c|c|c|}
\hline & Ch-W & Asf & AsfCN \\
\hline \multicolumn{4}{|l|}{ Thomas } \\
\hline$k_{\mathrm{Th}}\left(\mathrm{L} \mathrm{h}^{-1} \mathrm{mg}^{-1}\right)$ & $1498 \pm 384$ & $1702 \pm 362$ & $1552 \pm 354$ \\
\hline$q_{\mathrm{Th}} / \mathrm{mg} \mathrm{g}^{-1}$ & $0.898 \pm 0.120$ & $1.813 \pm 0.077$ & $2.655 \pm 0.088$ \\
\hline$R^{2}$ & 0.937 & 0.957 & 0.950 \\
\hline$\chi^{2}$ & 0.670 & 0.587 & 0.542 \\
\hline \multicolumn{4}{|l|}{ Yoon-Nelson } \\
\hline$t_{50}(\min )$ & $5.32 \pm 0.74$ & $12.12 \pm 0.52$ & $16.99 \pm 0.56$ \\
\hline $\begin{array}{l}t_{50} \text { Experimental } \\
(\mathrm{min})\end{array}$ & $4.41 \pm 0.51$ & $11.34 \pm 0.44$ & $16.06 \pm 0.37$ \\
\hline$k_{\mathrm{YN}}\left(\min ^{-1}\right)$ & $0.366 \pm 0.094$ & $0.416 \pm 0.088$ & $0.379 \pm 0.086$ \\
\hline$R^{2}$ & 0.937 & 0.957 & 0.951 \\
\hline$\chi^{2}$ & 0.670 & 0.587 & 0.542 \\
\hline \multicolumn{4}{|l|}{ DRM } \\
\hline$a(-)$ & $1.501 \pm 0.096$ & $4.617 \pm 0.672$ & $6.013 \pm 1.035$ \\
\hline$q_{\mathrm{DRM}}\left(\mathrm{mg} \mathrm{g}^{-1}\right)$ & $0.805 \pm 0.034$ & $1.950 \pm 0.061$ & $2.881 \pm 0.078$ \\
\hline$R^{2}$ & 0.996 & 0.975 & 0.965 \\
\hline$\chi^{2}$ & 0.110 & 0.381 & 0.393 \\
\hline \multicolumn{4}{|l|}{ BDST } \\
\hline $\begin{array}{l}k_{\mathrm{BDST}} \\
\quad\left(\mathrm{L} \mathrm{mg}^{-1} \mathrm{~min}^{-1}\right)\end{array}$ & $0.416 \pm 0.108$ & $0.472 \pm 0.050$ & $0.4312 \pm 0.099$ \\
\hline$N_{0}\left(\mathrm{mg} \mathrm{L}^{-1}\right)$ & $338.3 \pm 47.1$ & $770.3 \pm 32.8$ & $1080.2 \pm 36.3$ \\
\hline$R^{2}$ & 0.937 & 0.957 & 0.950 \\
\hline$\chi^{2}$ & 0.670 & 0.581 & 0.540 \\
\hline
\end{tabular}

Yoon-Nelson, and BDST) predicted the breakthrough curve shape in virtually the same way.

The maximum adsorption capacity predicted by Thomas $\left(q_{\mathrm{Th}}\right)$ and DRM ( $\left.q_{\mathrm{DRM}}\right)$ models is similar but lower than the experimental value. Also Yoon-Nelson model miscalculated the performance of adsorbents. Value of the $t_{50}$ parameter (time at which $C_{t} / C_{0}=0.05$ ) for all adsorbents was lower than experimental.

The rate constant $k_{\mathrm{BDST}}$ calculated by BDST model describes the rate of adsorbate transfer from the gas phase to the solid phase. It increased for both asphaltene adsorbents as compared to $\mathrm{Ch}-\mathrm{W}$, but for AsfCN, it is lower than for Asf. The $N_{0}$ parameter characterizes the adsorption capacity of the bed per unit bed volume. Since it is correlated with adsorption capacity, it is not a surprise that AsfCN adsorbent has the highest $N_{0}$ value.

Above-mentioned results and former literature reports on utilization of asphaltenes for waste gas purification indicate that the presented application can be used in petrochemical industry for adsorption of volatile compounds containing sulfur, nitrogen, oxygen, as well as aromatic hydrocarbons. These compounds are typically present in waste gases emitted from process streams (Boczkaj et al. 2016a; Boczkaj et al. 2017; Makos et al. 2018a, b).

\section{Scale-up of packed bed adsorption column}

For scaling-up of the adsorption column, the kinetic equation and experimental breakthrough data from laboratory column were used. The assumption was made that breakthrough occurs at $\mathrm{C} / C_{0}$ equal to 0.05 , influent concentration is equal to laboratory experiment (i.e. $0.88 \mathrm{mg} \mathrm{L}^{-1}$ ), volumetric flow rate of designed column is $2000 \mathrm{~m}^{3} \mathrm{~h}^{-1}$, required breakthrough volume is equal to $10,000 \mathrm{~m}^{3}$, and unit gas flowrate is the same as in laboratory scale column, i.e., $241 \mathrm{~L} \mathrm{~s}^{-1} \mathrm{~m}^{-2}$. Table 7 gives calculated parameters of scaled-up columns.

Aforementioned results of adsorption column scaling-up clearly indicate that favorable adsorption characteristics of asphaltene-based adsorbents (especially AsfCN) lead to substantial reduction of the size of a potential adsorption unit in case of process-scale operations. Results revealed that

Table 7 Calculated parameters of the scaled-up columns

\begin{tabular}{llll}
\hline Parameter & \multicolumn{2}{l}{ Adsorbent } & \\
\cline { 2 - 4 } & Ch-W & Asf & AsfCN \\
\hline$\rho_{\text {bed }}\left(\mathrm{kg} \mathrm{m}^{-3}\right)$ & 404 & 400 & 409 \\
$M(\mathrm{~kg})$ & 21,651 & 5570 & 3572 \\
$V_{\text {bed }}\left(\mathrm{m}^{3}\right)$ & 53.59 & 13.93 & 8.73 \\
$D(\mathrm{~m})$ & 1.71 & 1.71 & 1.71 \\
$H(\mathrm{~m})$ & 23.25 & 6.04 & 3.79 \\
\hline
\end{tabular}


application of the $10 \mathrm{wt} \%$ cyanated asphaltene-based adsorbent reduced the required adsorbent's mass over six times. It is of utmost importance when considering economic feasibility. The advantageous characteristic of asphaltene-based adsorbents can be further improved using a different support with higher surface area.

\section{Conclusions}

These studies revealed that small quantities of asphaltenes can be effectively used as an adsorption active component for removal of toxic volatile organic compounds from the gas phase. Moreover, it was proved that feasible chemical modification significantly enhanced performance of asphaltene adsorbents. Classification by Rohrschneider-McReynolds constants showed that overall strength of interactions increased more than two times. The biggest change was observed for pyridine. Cyanation increased the value of the dispersive and specific components of the surface-free energy from 106 to $118 \mathrm{~mJ} \mathrm{~m}^{-2}$ and from 30 to $52 \mathrm{~mJ} \mathrm{~m}^{-2}$, respectively. Dispersive component's value is comparable to silica or alumina. Moreover, modification resulted in increased concentration of both acidic and basic adsorption centers on the adsorbent's surface. It indicates that asphaltene adsorbents can be effective in removal of both alkaline and acidic gases.

Analysis of adsorption isotherms reveals that monolayer capacity was increased by $56 \%$ after modification. The adsorption process was better described by the Freundlich model and results suggest that energetically heterogeneous characteristic of the adsorbent's surface did not change significantly upon chemical modification.

Breakthrough curves have explicitly demonstrated the applicability of asphaltenes to adsorption processes and waste gas purification. Calculated operational parameters indicate significant increase in performance of modified asphaltene adsorbent. Results of scale-up calculations revealed that mass of adsorbents required to achieve desired pyridine removal decreased from 21651 for uncoated support to 5570 and $3572 \mathrm{~kg}$ for raw asphaltene adsorbent and cyanated asphaltene adsorbent, respectively. Hence, the chemical modification leads not only to enhanced adsorption properties of asphaltenes but also to higher economic feasibility, in case of potential process-scale applications.

Above-mentioned advantages of asphaltene adsorbents: undesired by-product, facile isolation and chemical modification methods, strong adsorbent-adsorbate interactions of asphaltenes, and its chemically modified derivative seem to be an effective and low-cost adsorbent for waste gas purification. Further developments in asphaltene-based adsorbents are required-inexpensive porous support (with high surface area) will further facilitate their performance.

Acknowledgements The authors gratefully acknowledge the financial support from the National Center for Research and Development, Warsaw, Poland-Project LIDER, no. LIDER/036/573/L-5/13/ NCBR/2014. This work was financially supported by the project "INTERPHD2" no. POWR.03.02.00-IP.08-00-DOC/16.

Open Access This article is distributed under the terms of the Creative Commons Attribution 4.0 International License (http://creativeco mmons.org/licenses/by/4.0/), which permits unrestricted use, distribution, and reproduction in any medium, provided you give appropriate credit to the original author(s) and the source, provide a link to the Creative Commons license, and indicate if changes were made.

\section{References}

Akbarzadeh K, Hammani A, Zhang D, Alleson S, Creek J, Kabir S, Jamaluddin AJ, Marshall AG, Rodgers RP, Mullins OC, Solbakken T (2007) Asphaltenes-problematic but rich in potential. Oilf Rev 19:22-43

Ali MF, Siddiqui MN, Al-Hajji AA (2004) Structural studies on residual fuel oil asphaltenes by RICO method. Pet Sci Technol 22:631-645. https://doi.org/10.1081/LFT-120034205

Belaissaoui B, Le Moullec Y, Favre E (2016) Energy efficiency of a hybrid membrane/condensation process for VOC (volatile organic compounds) recovery from air: a generic approach. Energy 95:291-302. https://doi.org/10.1016/j.energy.2015.12.006

Boczkaj G, Makoś P, Fernandes A, Przyjazny A (2016a) New procedure for the control of the treatment of industrial effluents to remove volatile organosulfur compounds. J Sep Sci 39:39463956. https://doi.org/10.1002/jssc.201600608

Boczkaj G, Momotko M, Chruszczyk D, Przyjazny A, Kamiński M (2016b) Novel stationary phases based on asphaltenes for gas chromatography. J Sep Sci 39:2527-2536. https://doi.org/10.1002/ jssc. 201600183

Boczkaj G, Makoś P, Fernandes A, Przyjazny A (2017) New procedure for the examination of the degradation of volatile organonitrogen compounds during the treatment of industrial effluents. J Sep Sci 40:1301-1309. https://doi.org/10.1002/jssc.201601237

Carbognani L, Espidel J (2003) Preparative subfractionation of petroleum resins and asphaltenes. II. Characterization of size exclusion chromatography isolated fractions. Pet Sci Technol 21:17051720. https://doi.org/10.1081/LFT-120024558

Díaz E, Ordóñez S, Vega A, Coca J (2004) Adsorption characterisation of different volatile organic compounds over alumina, zeolites and activated carbon using inverse gas chromatography. J Chromatogr A 1049:139-146. https://doi.org/10.1016/j.chroma.2004.07.061

Díaz E, Ordóñez S, Vega A (2007) Adsorption of volatile organic compounds onto carbon nanotubes, carbon nanofibers, and highsurface-area graphites. J Colloid Interface Sci 305:7-16. https:// doi.org/10.1016/j.jcis.2006.09.036

Dorris GM, Gray DG (1980) Adsorption of $n$-alkanes at zero surface coverage on cellulose paper and wood fibers. J Colloid Interface Sci 77:353-362. https://doi.org/10.1016/0021-9797(80)90304-5

Elzhov TV, Mullen KM, Spiess AN, Bolker B (2016) minipack.lm: $\mathrm{R}$ interface to the Levenberg-Marquardt nonlinear least-squares algorithm found in MINPACK, plus support for bounds

EU (2004) Directive 2004/42/CE on the limitation of emissions of volatile organic compounds due to the use of organic solvents in certain paints and varnishes and vehicle refinishing products 
Gospodarek M, Rybarczyk P, Szulczyński B, Gębicki J (2019) Comparative evaluation of selected biological methods for the removal of hydrophilic and hydrophobic odorous VOCs from air. Processes 7:1-22. https://doi.org/10.3390/pr7040187

Groenzin H, Mullins OC (2000) Molecular size and structure of asphaltenes from various sources. Energy Fuels 14:677-684. https ://doi.org/10.1021/ef990225z

Huang H, Xu Y, Feng Q, Leung DYC (2015) Low temperature catalytic oxidation of volatile organic compounds: a review. Catal Sci Technol 5:2649-2669. https://doi.org/10.1039/c4cy01733a

Huber JFK, Gerritse RG (1971) Evaluation of dynamic gas chromatographic methods for the determination of adsorption and solution isotherms. J Chromatogr A 58:137-158. https://doi.org/10.1016/ S0021-9673(00)96607-X

Hutchins R (1973) New method simplifies desing of activated carbon systems. Chem Eng 80:133-138

James AT, Martin AJP (1952) Gas-liquid partition chromatography. A technique for the analysis of volatile materials. Analyst 77:915932. https://doi.org/10.1039/AN9527700915

Jaroniec M (1975) Adsorption on heterogeneous surfaces: the exponential equation for the overall adsorption isotherm. Surf Sci 50:553-564

Kipping PJ, Winter DG (1965) Measurement of adsorption isotherms by a gas chromatographic technique. Nature 205:1002-1003

Langmuir I (1918) The adsorption of gases on plane surfaces of glass, mica and platinum. J Am Chem Soc 40:1361-1403

Lin CC, Wei TY, Hsu SK, Liu WT (2006) Performance of a pilot-scale cross-flow rotating packed bed in removing VOCs from waste gas streams. Sep Purif Technol 52:274-279. https://doi.org/10.1016/j. seppur.2006.05.003

Makoś P, Fernandes A, Boczkaj G (2018a) Method for the simultaneous determination of monoaromatic and polycyclic aromatic hydrocarbons in industrial effluents using dispersive liquid-liquid microextraction with gas chromatography-mass spectrometry. J Sep Sci 41:2360-2367. https://doi.org/10.1002/jssc.201701464

Makoś P, Fernandes A, Przyjazny A, Boczkaj G (2018b) Sample preparation procedure using extraction and derivatization of carboxylic acids from aqueous samples by means of deep eutectic solvents for gas chromatographic-mass spectrometric analysis. J Chromatogr A 22:10-19. https://doi.org/10.1016/j.chroma.2018.04.054

Malhotra VM, Buckmaster HA (1989) 34 GHz EPR FTIR spectra of chromatographically separated Boscan asphaltene fractions. In: Preprints from ACS symposium on trace elements in petroleum geochemistry

Mellouki A, Wallington TJ, Chen J (2015) Atmospheric chemistry of oxygenated volatile organic compounds: impacts on air quality and climate. Chem Rev 2015:3984-4014. https://doi.org/10.1021/ cr500549n

Mullins OC (2010) The modified Yen model. Energy Fuels 24:2179_ 2207. https://doi.org/10.1021/ef900975e

Mullins OC (2011) The asphaltenes. Annu Rev Anal Chem 4:393-418. https://doi.org/10.1146/annurev-anchem-061010-113849

Plata-Gryl M, Jungnickel C, Boczkaj G (2018) An improved scalable method of isolating asphaltenes. J Pet Sci Eng 167:608-614. https ://doi.org/10.1016/j.petrol.2018.04.039

Plata-Gryl M, Momotko M, Makowiec S, Boczkaj G (2019) Highly effective asphaltene-derived adsorbents for gas phase removal of volatile organic compounds. Sep Purif Technol 224:315-321. https://doi.org/10.1016/j.seppur.2019.05.041

$\mathrm{R}$ : a language and environment for statistical computing (2008. https ://cran.r-project.org/web/packages/minpack.lm/minpack.lm.pdf
Saint Flour C, Papirer E (1982) Gas-solid chromatography: a method of measuring surface free energy characteristics of short glass fibers. 2. Through retention volumes measured near zero surface coverage. Ind Eng Chem Prod Res Dev 21:666-669. https://doi org/10.1021/i300008a031

Sarigiannis DA, Karakitsios SP, Gotti A, Liakos IL, Katsoyiannis A (2011) Exposure to major volatile organic compounds and carbonyls in European indoor environments and associated health risk. Environ Int 37:743-756. https://doi.org/10.1016/j.envin t.2011.01.005

Schuler B, Meyer G, Peña D, Mullins OC, Gross L (2015) Unraveling the molecular structures of asphaltenes by atomic force microscopy. J Am Chem Soc 137:9870-9876. https://doi.org/10.1021/ jacs.5b04056

Thomas HC (1944) Heterogeneous ion exchange in a flowing system. J Am Chem Soc 66:1664-1666

Tijburg I, Jagiello J, Vidal A, Papirer E (1991) Inverse gas chromatographic studies on silica: infinite dilution and finite concentration measurements. Langmuir 7:2243-2247. https://doi.org/10.1021/ la00058a044

van Oss CJ (1993) Acid-base interfacial interactions in aqueous media. Colloids Surfaces A Physicochem Eng Asp 78:1-49. https://doi. org/10.1016/0927-7757(93)80308-2

van Oss CJ, Good RJ, Chaudhury MK (1988) Additive and nonadditive surface tension components and the interpretation of contact angles. Langmuir 4:884-891. https://doi.org/10.1021/la00082a01 8

Vidal A, Papirer E, Wang MJ, Donnet JB (1987) Modification of silica surfaces by grafting of alkyl chains. I-Characterization of silica surfaces by inverse gas-solid chromatography at zero surface coverage. Chromatographia 23:121-128. https://doi.org/10.1007/ BF02312887

Voelkel A, Strzemiecka B, Adamska K, Milczewska K (2009) Inverse gas chromatography as a source of physiochemical data. J Chromatogr A 1216:1551-1566. https://doi.org/10.1016/j.chrom a.2008.10.096

Wilt BK, Welch WT, Graham Rankin J (1998) Determination of asphaltenes in petroleum crude oils by fourier transform infrared spectroscopy. Energy Fuels 12:1008-1012. https://doi. org/10.1021/ef980078p

Yan G, Viaraghavana T, Chen M (2001) A new model for heavy metal removal in a biosorption column. Adsorpt Sci Technol 19:25-43. https://doi.org/10.1260/0263617011493953

Yoon YH, Nelson JH (1984) Application of gas adsorption kinetics. I. A theoretical model for respirator cartridge service life. Am Ind Hyg Assoc 45:509-516. https://doi.org/10.1080/1529866849 1400197

Zhang X, Gao B, Zheng Y, Hu X, Creamer AE, Annable MD, Li Y (2017) Biochar for volatile organic compound (VOC) removal: sorption performance and governing mechanisms. Bioresour Technol 245:606-614. https://doi.org/10.1016/j.biort ech.2017.09.025

Publisher's Note Springer Nature remains neutral with regard to jurisdictional claims in published maps and institutional affiliations. 


\section{Affiliations}

\section{Maksymilian Plata-Gryl ${ }^{1}$ (D) Malwina Momotko ${ }^{1} \cdot$ Sławomir Makowiec $^{2}$ (D) $\cdot$ Grzegorz Boczkaj $^{1}$ (D)}

$\triangle$ Grzegorz Boczkaj grzegorz.boczkaj@pg.edu.pl

1 Department of Process Engineering and Chemical Technology, Faculty of Chemistry, Gdansk University of Technology, G. Narutowicza St. 11/12, 80-233 Gdańsk, Poland
2 Department of Organic Chemistry, Faculty of Chemistry, Gdansk University of Technology, 80-233 Gdańsk,

G. Narutowicza St. 11/12, Poland 